\title{
Construção, desconstrução e reconstrução de sistemas de valores nas organizações
}

\author{
Paulo Reis Vieira ${ }^{1}$ \\ Antonio Semeraro Rito Cardoso²
}

\section{Resumo}

Este trabalho tem como objetivo promover uma reflexão sobre o que, costumeiramente, é denominado de "valor organizacional". Também busca ampliar o conhecimento quanto aos mecanismos de construção e reconstrução de valores nas organizações. Analisa quais as nuances que envolvem essa complexa teia de construção dos valores individuais, como eles se interligam num processo contínuo de construção e reconstrução e de que forma interagem no contexto organizacional, construindo a singularidade organizacional. Para fundamentar essa análise, os autores se valeram de pesquisa sobre o tema, com a colaboração de organizações, buscando averiguar 0 entendimento comum sobre 0 assunto. Identificou-se uma tendência à idéia de que os valores organizacionais são gerados pela própria organização, como se essas fossem entes independentes e com vida própria, capazes de gerar valores organizacionais, impondo-os a seus colaboradores e ao mercado. Refletir sobre valores organizacionais versus valores individuais - e seu processo de construção e reconstrução em busca do que chamamos de singularidade organizacional - constitui a essência deste trabalho.

Palavras-chave: Valores organizacionais, organizações dinâmicas, mudança organizacional

\begin{abstract}
The object of this work is to reflect on the question of what is generally refered to as organizational values. It also aims to develop and expand our understanding of the mechanisms of construction and reconstruction of values within organizations. The work tries to identify the nuances woven into this complex web of construction of individual values and how they are inter-linked within the continuous process of construction and reconstruction and the manner in which they interact within the organizational context establishing a system of organizational singularity. The authors thus identified a common view that organizational values are generated by the organizations themselves, almost as if they were individual beings with a life of their own capable of generating organizational values and then imposing them on those they employ and the market. The essence of this work was therefore to reflect on organizational values versus individual values and the process leading to their construction and reconstruction in the search for what we call organizational singularity.
\end{abstract}

Keywords: Organizationals values, dinamics organizations, organizational change

\section{Introdução}

Nas organizações, tem sido verificado o uso cada vez mais freqüente de inúmeras ferramentas de gestão, fruto da necessidade de adequação dos processos à velocidade das mudanças no ambiente econômico, político e social. Assim, um número infindável de ferramentas permeia a ação dos gestores, que, em última instância, sempre priorizam algo em prejuízo de outro. Nesse ponto, é inquestionável a importância de se compreender melhor o impacto dos valores individuais, e, porventura, organizacionais, sobre o que acontece nas organizações públicas e privadas, levando em consideração, sobretudo, as conseqüências sobre as relações sociais.

1 Professor Titular da Escola Brasileira de Administração Pública e de Empresas da Fundação Getulio Vargas. PhD em Administração Pública pela University of Southern California. Mestre em Administração Pública pela University of Southern California. Mestre em Administração Pública pela University of Denver. Bacharel em Ciências Jurídicas e Sociais pela UFRJ. E-mail:preis@ fgv.b.

2 Professor da Escola Brasileira de Administração Pública e de Empresas da Fundação Getulio Vargas. Mestre em Administração Pública, pela EBAPE/FGV, Especialista em Administração Publica, pela EBAPE/FGV, Especialista em Ciência Política, pelo Instituto Metodista Bennett, Graduado em Economia, pela Universidade Cândido Mendes. E-mail: arito@ fgv.br. 
Nesse contexto, é importante perceber que a aplicação eficiente de ferramentas de gestão não significa que essas organizações sobreviverão e serão bem-sucedidas. Perceber os indivíduos com seus valores, crenças, sonhos e expectativas - e como agentes ativos da organização -, é entender que eles é que serão os verdadeiros instrumentos de ação, desde o momento que aceitem e compreendam, a partir de seus valores, esses instrumentais como necessários para a manutenção de certa vantagem ou como instrumento para levar a organização a níveis de maior eficiência e eficácia.

Ademais, por estar inserida no campo das ciências sociais, a administração se caracteriza como ciência social aplicada. Isso significa que todas as categorias de análise utilizadas pela sociologia, psicologia, ciência política, economia, entre outras, aplicam-se aos estudos do fenômeno administrativo, com destaque, por exemplo, para a questão dos valores.

A convicção e o conhecimento quanto ao impacto dos valores sobre a vida organizacional - sabendo-se inequivocamente que as organizações definem as tarefas e o uso das ferramentas de gestão através de formas de modelagem organizacional - estão fundamentados (e se ampliaram) na convivência com consultores e professores, o que permite concluir, dentre outras considerações, que as organizações são singulares, mas que a singularidade organizacional resulta de um complexo processo de construção, desconstrução e reconstrução de sistemas de valores.

Verificou-se também, e principalmente, que o que se pode chamar de valor organizacional constitui algo singular - a singularidade organizacional - que distinguirá uma determinada organização de todas as outras. Essa singularidade será entendida como tal pela multiplicidade de percepções que, à primeira vista, paradoxalmente, a ela conduza.

Além disso, pode-se perceber que a arquitetura organizacional - mesmo quando se constroem modelos bastante abrangentes, contemplando o maior número possível de variáveis - não direciona e nem garante a transformação organizacional, por ser incapaz de dar conta da subjetividade humana em relação aos valores organizacionais.

Ademais, a literatura sobre valores na área de gestão tem se apresentado de forma precária, principalmente, por não ter se beneficiado de pesquisas já realizadas em psicologia, sociologia e filosofia.

Como já visto, a administração é uma ciência social aplicada. Assim, no que diz respeito aos valores, os estudos organizacionais têm enfatizado a construção de escalas para mensurarmos valores e formas prescritivas de comportamento.

Sem desdenhar totalmente dessas abordagens - já que poderão contribuir para a clarificação do assunto -, há, porém, de se perceber a existência de lacunas e visões reducionistas sobre a importância dos valores individuais no processo de gestão das organizações.

\section{Em busca da compreensão sobre a singularidade organizacional}

A compreensão sobre o que vem a ser valor organizacional parte de nossa premissa de que as organizações existem para que tarefas sejam distribuídas e executadas. Em última análise, as tarefas são distribuídas e executadas por pessoas. As pessoas levam consigo, para onde forem, sua escala social ou ética de valores. Compreender como os valores inerentes a cada pessoa interagem na organização - e de que forma são construídos e reconstruídos a partir da interação com os valores de outrem e daqueles que gerenciam a organização - pode ser da maior importância no processo de condução das organizações para a realização de seus objetivos.

Pretendemos lançar alguma luz nessa eterna discussão sobre a existência de um valor organizacional em contraponto com valores pessoais. Neste estudo, definimos como valor organizacional algo singular, que passaremos a denominar singularidade organizacional, que distinguirá determinada organização de todas as outras e será entendida como tal pela multiplicidade de percepções que sua singularidade agrega. 


\section{Turbulência na construção}

Parece imprópria a busca de conceituação de valores, já que o assunto se vulgarizou nas diversas correntes filosóficas, psicológicas, sociológicas, políticas e até mesmo econômicas.

A despeito das turbulências, percebemos algumas associações que, embora descontínuas e às vezes aparentemente espúrias e superpostas, têm ajudado em nosso crescimento pessoal e profissional. Exemplificando, percebemos manifestações de contemplação e/ou preocupação hedonística, em que o valor se concentra em proporcionar bem-estar, prazer, deleite. Não se trata de exclusão de outras buscas, outros valores, mas de procurar eliminar tudo o que deixe de ser prazeroso, sem que seja mensurado o elemento desencadeador do prazer e haja preocupação em transformá-lo em dinheiro ou algo equivalente.

As turbulências se acentuam quando, por exemplo, verificamos em muitas situações dentro e fora das organizações em que atuamos, alguma dissociação entre falas ou discursos e ações ou comportamentos individuais e grupais visíveis; configurando, por ventura, abordagem e compreensão platônica ou platonizante, enunciando-os como idealizações inconsistentes. Desse modo, é dificultado o ápice da conquista e, consequentemente, do alcance da singularidade.

O nominalismo, ao estabelecer a subjetividade como a essência dos valores, aumenta a turbulência conceitual. Aqui, só o indivíduo importa.

\section{Construção e reconstrução "chegantes" à singularidade}

Temos observado em nosso cotidiano o singular e o plural; a singularidade e a multiplicidade em convivência supostamente antagônica. Na realidade, a multiplicidade de valores conduz à singularidade. Dessa forma, como clarificar esse processo de construção, que como vimos é turbulento, complexo e sinuoso?

Inicialmente, devemos olhar para nós mesmos e para quem está ao nosso lado. Mesmo se nossas lentes estiverem embaçadas por não trabalharmos o inconsciente, em nível de consciência percebemos predominâncias em nossos sistemas de valores, a despeito de alguns deles perderem vigor e força diante de contradições circunstanciais provenientes do ego, dos outros e de ambiências diversas. Tudo isso acontece. A associação entre todos esses valores - os predominantes e os amortecidos, múltiplos e descontínuos em suas manifestações - traçam, porém, a singularidade individual, grupal e organizacional.

Olhemos à volta. Percebemos no outro valores semelhantes aos nossos: amor ao próximo, respeito à ordem e à hierarquia, lealdade e doação de tempo e disponibilidade para trocas nos níveis intelectual, emocional, afetivo e físico. No entanto, apesar desses valores, o processo de construção e reconstrução se apresenta em sua turbulenta plenitude. De repente, o amor ao próximo se transforma em manipulação, a contestação e a sublevação se instalam contra a ordem, e a subserviência se compraz com ela; lealdade é substituída por hostilidade; tempo e disponibilidade se reduzem ou se eliminam impedindo as trocas.

Ampliemos o campo do olhar. Nosso foco passa a perscrutar a organização como um todo. Valores, só os do indivíduo. Dessa forma não há como fazer referência a valores organizacionais, desconsiderando qualquer processo de construção, desconstrução e reconstrução de valores. Juntamente com essa reflexão, a turbulência já se transforma em turbilhão de compreensão múltipla da singularidade. Não importa se valores se associarão ao ideal e à subjetividade ou, em outra direção, ao real e ao concreto. Valores valem por si mesmo. Surgem em dicotomias à nossa escolha como beleza versus feiura, bondade versus maldade, amor versus ódio e várias outras, em que nada surge como opostos mas posições alternadas entre valores.

Portanto, não adianta buscar uma única conceituação de valores, inquestionável e aceitável por todos. O que importa é aceitar e viver as turbulências inerentes ao nossos próprios sistemas de valores, aos dos outros e aos da organização, para podermos abandonar a perspectiva tradicional das práticas gerenciais que, por sua vez, conduzem ao ensino repetitivo, conservador e mantenedor de formatos igualmente tradicionais. Nesse sentido, rupturas só ocorrem através do enfrentamento do sistema de valores predominante. 


\section{Singularidade organizacional}

Para que se entenda essa singularidade organizacional, demonstraremos como os valores individuais são construídos e reconstruídos e de que forma interagem a partir do contato com outros valores. Então, será possível levarmos esse processo de entendimento para o plano das organizações.

Os valores individuais podem ser divididos em duas vertentes. A primeira refere-se aos valores que nascem com os indivíduos, representam a herança genética dos antepassados e estão gravados no código genético. A segunda diz respeito àqueles que foram adquiridos ao longo da vida através da educação, seja ela formal ou informal, e da forma com que o mundo é percebido. A interação dos valores genéticos com os valores adquiridos e percebidos forma o cadinho da construção e reconstrução dos valores individuais.

Os valores individuais, fruto dessa construção/reconstrução, formarão a base de ação comportamental para que os indivíduos, sujeitos ou não de sua história, busquem realizar seus anseios e aspirações na construção da vida. Dessa forma, entender as ações das pessoas é procurar entender, antes de mais nada, os valores individuais externalizados através da ação de construção do mundo. Esse entendimento passa não só pela compreensão da realidade presente, como também do passado, pois ninguém vive inteiramente no presente. $\mathrm{O}$ passado e a tradição da raça e do povo, vivem nas ideologias de cada indivíduo, e só lentamente cedem às influências do presente, no sentido de novas mudanças.

É importante o entendimento de que não viver inteiramente no presente demonstra que - além do físico, nas dimensões temporal e material - as emoções oscilam entre o passado e o presente, também avançando para o futuro; numa visão tridimensional, recuperando, construindo e reconstruindo valores.

Portanto, observamos que a despeito das influências genéticas e da história de vida, os valores são, até certo ponto, escolhidos pelos indivíduos. Logo, importa enfatizar que é inerente à condição humana certa margem de arbítrio que permita aos indivíduos tomar decisões com base em sua própria vontade e capacidade de mudança de seus sistemas de valores.

\section{Turbulências no caminho da construção e reconstrução de valores}

Até aqui, ao nos aventurarmos na reflexão sobre valores, sejam de vida ou profissionais/organizacionais, percebemos claramente a impossibilidade de abrirmos mão de nossas próprias valorizações. Assim, este trabalho traz consigo preferências, prioridades e subjetividades, conduzindo-nos a algumas questões indicadoras de turbulências no percurso da construção/reconstrução e do aprendizado/reaprendizado de valores.

Perguntamos, então: para que estudar e discutir valores? A que serve e a quem é útil? Nessa discussão, haverá, inexoravelmente, posicionamentos ingênuos, românticos ou frágeis, decorrentes de sua obviedade? Nesse ponto, de algum modo e com intensidade não desprezível, pensar sobre o tema, incursionar na aventura de buscar ensiná-lo a outros representará a essência do conhecimento sobre o indivíduo, as relações interpessoais, os grupos, as organizações e a sociedade e seus valores. Com isso, contribuir-se-á para o enriquecimento da teoria geral de administração.

Nesse processo de identificação dos valores individuais é importante trazer à discussão o fato de que os valores verdadeiros são aqueles percebidos por terceiros. De nada valem os valores declarados pelo sujeito. Os valores só se tornam concretos e capazes de interagir com o ambiente quando concebidos em ação. Assim, definimos como valores as características individuais externalizadas por ações e percebidas por terceiros; de outro modo, não são considerados valores, e sim intenções.

Em última análise, valores declarados podem até corresponder à realidade das ações de quem os declara, mas precisam ser efetivados em ação para que aqueles que o percebem possam realmente verificá-lo. É importante lembrar que valores declarados podem, no fundo, ter como objetivo subverter ou confundir o ponto de vista de quem está tentando perceber determinada ação para inferir juízos de valor, com o objetivo de realizar novas construções a seu favor. Essas declarações podem até ser verdadeiras e servirem de base para ações de seu 
declarante, mas a base de valores na qual a declaração/ação está construída pode ser totalmente falsa do ponto de vista da observação de terceiros. Recentemente, vimos as declarações de um senador da República que afirmava ter somente violado um painel de votação e não roubado dinheiro como tantos o fazem nessa República. Esse constitui exemplo de declaração cujo objetivo é comparar fatos sem levar em consideração atos que são frutos de uma ação, na tentativa de reconstruir valores de seus espectadores e com isso reverter situações negativas em positivas. Outro exemplo flagrante no universo das organizações refere-se aos programas de qualidade total, cujo objetivo, muitas vezes, tem se constituído em obter certificação sem existência de processo de desconstrução e reconstrução de valores.

Outra situação bastante interessante e para a qual é preciso estar atento é quando a externalização de valores por um indivíduo, através de suas ações, corresponde a uma realidade parcial, num primeiro momento, e que pode perdurar por longo tempo. A característica dos valores desses indivíduos é a de não possuírem uma singularidade que permita a um conjunto de pessoas aceitar, chegar a um consenso sobre o valor percebido. Isso é comum nas personalidades narcísicas perversas, cujas ações de externalização de valores são ambíguas, que se passam por "boas" perante aqueles a quem conseguem cativar para atingir um fim perverso, e que só será percebido pelo agredido.

Suavizando a discussão, repetimos o poeta anônimo:

"Vigie seus pensamentos, porque eles se tornarão palavras; vigie suas palavras, porque elas se tornarão atos; vigie seus atos, porque eles se tornarão seus hábitos; vigie seus hábitos porque eles se tornarão seu caráter; vigie seu caráter porque ele será seu destino".

Ao transpormos essa visão para as organizações poderíamos inferir que estas são influenciadas pelos valores individuais (V1,V2,V3 - figura 1) de cada um de seus colaboradores. Esses valores individuais interagem com os outros valores individuais existentes na organização, gerando assim um processo de construção/reconstrução a todo o momento. A partir dessa interação, um novo valor é construído (valor coletivo - figura 1) e essa nova configuração passa a exercer influência nas ações empreendidas na organização.

Essa nova variável de valor, singular a esse conjunto de pessoas que se encontram na organização, em determinado espaço de tempo e lugar, poderá ser monitorada pelos gestores das organizações (valores dos gestores - figura 1), de forma a compor a singularidade desejada às características do negócio em determinado momento (área de construção - figura 1).

\section{Percepção externa}

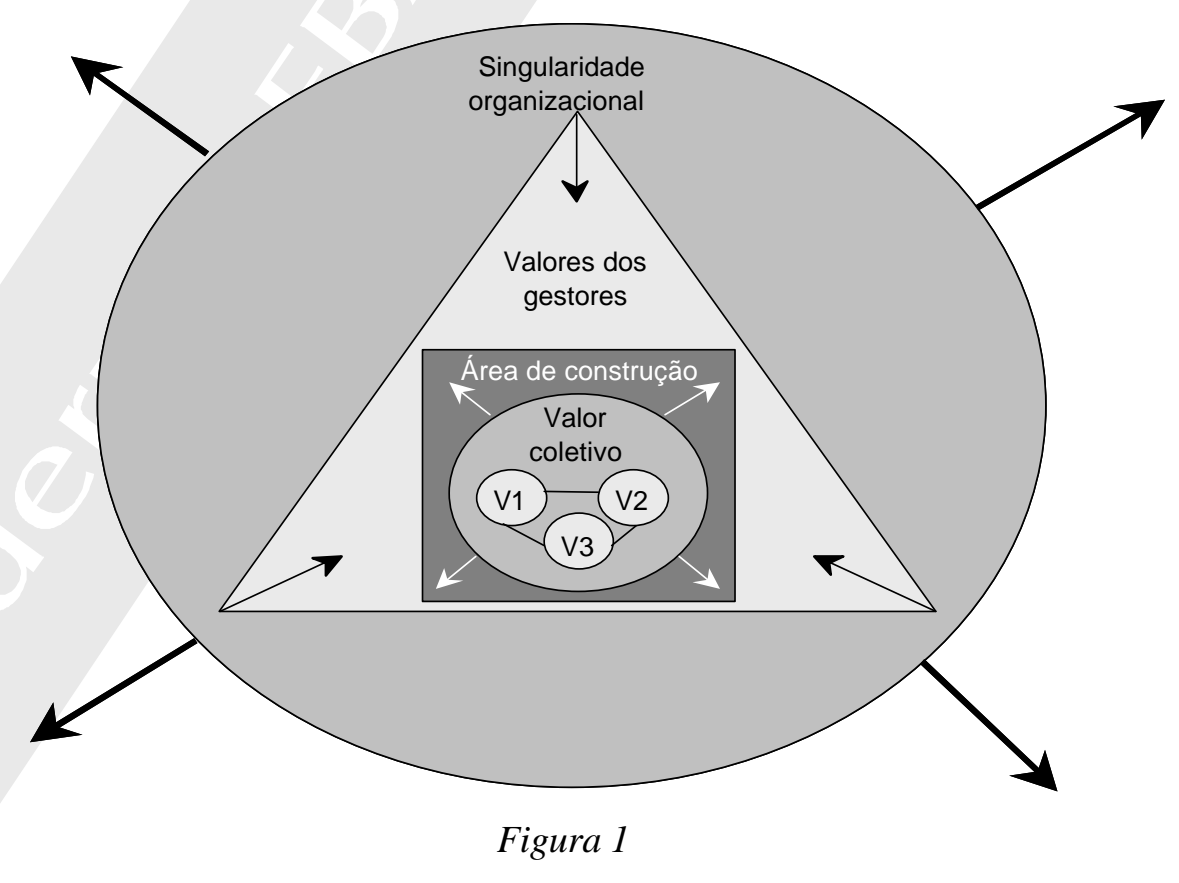


Da mesma forma que os valores individuais (V1) interagem com outros valores individuais (V2) dentro das organizações, gerando novos valores - o que chamamos de processo de construção/reconstrução dos valores -, os dirigentes/acionistas procurarão interagir com esse grupo que, a partir de sua interação, adquire novo valor, singular, de forma a atuar como vetor de influência na construção de valor considerado desejável (percepção externa da organização) à concretização dos desígnios organizacionais, em busca de equilíbrio da singularidade.

Esse equilíbrio será sempre inconstante (figura 2), podendo a singularidade da organização se afastar do que seria considerado ideal para seus dirigentes/acionistas. Assim, os gestores das organizações estarão sempre agindo no sentido de propiciar novas reconstruções de valores, visando o predomínio dos seus próprios valores, na busca da singularidade organizacional e do ponto de equilíbrio desejado por eles.

A importância desse ponto de equilíbrio da singularidade organizacional está na agregação da enorme multiplicidade de valores que o compõem, cujas características seriam positivas para a realização dos objetivos da organização e suficientemente múltiplas para serem percebidas pelos diversos atores externos à organização como singular.

Contudo, a busca desse equilíbrio não é simples, pois esse processo não é ordeiro nem pacífico. Implica mudanças constantes que podem estar sujeitas a resistências, fruto da saída dos indivíduos da sua zona de conforto, e implicar rupturas na estrutura de poder.

\section{Percepção externa}

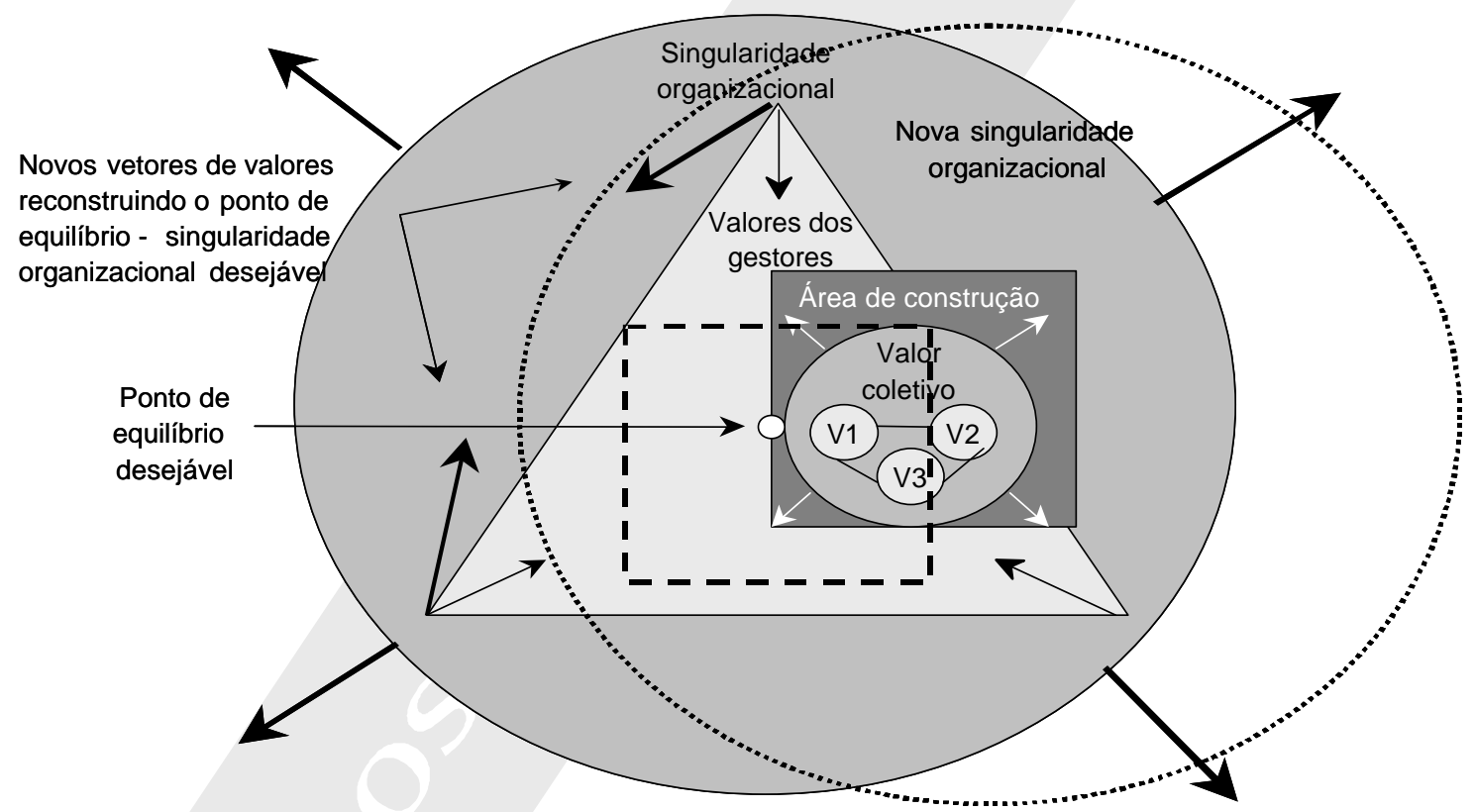

Figura 2 


\section{Gerenciando valores}

Gerenciar valores desponta como atribuição e responsabilidade intransferíveis dos gestores e acionistas, em virtude da busca de singularidade organizacional. Assim, urge ser simples e ágil, a fim de que a gerência de valores se transforme em instrumento de gestão.

Nesse campo, acreditamos que o processo de avaliação possa significar um caminho interessante, desde que as práticas tradicionais de avaliação - nas quais predomina a preocupação em auferir a produtividade dos indivíduos - sejam abandonadas e substituídas por outras destinadas a avaliar questões subjetivas. Só assim acreditamos no processo de avaliação da objetividade.

Tal processo pode ocorrer em diversos níveis. Pode ser individual ou coletivo, e abranger todo o universo da organização (dos colaboradores aos clientes), todos os níveis hierárquicos e em todos os sentidos. Em primeiro lugar, a avaliação não pode prescindir da auto-avaliação, a qual seria validada pela heteroavaliação, requerendo processo de discussão em que a singularidade da organização seria discutida por todos, inclusive os clientes.

O processo de construção precisa levar em consideração a identificação das lideranças na organização como elementos facilitadores da construção e reconstrução dos valores, caminho indispensável à mudança.

Outro fator importante são as relações de poder na luta pela supremacia dos valores. A interação de dois indivíduos nunca estará em equilíbrio, pois existirá sempre a predominância de um sobre outro, o que pode ocorrer por vários fatores. O importante é que ocorre e tem de ser levada em consideração quando analisamos a interação de valores. Abordagens psicológicas afirmam no campo das relações interpessoais a existência de subordinação ou comando entre dois. No cotidiano, existe a troca entre duas posições. Um se subordina ao outro, e vice-versa, aí se configurando, em termos psicológicos, a real situação de "co-laboração", isto é, labor a dois.

O mesmo ocorre dentro das organizações. Pode existir relação de desequilíbrio entre os vetores que emanam da interação dos valores individuais, o que faz com que a singularidade da organização tenda a ficar fora do ponto de equilíbrio, roubando da organização o caráter universal da sua singularidade. O mesmo ocorre quando a relação de força se torna desequilibrada, partindo dos dirigentes/acionistas em direção à singularidade gerada pelos valores individuais, com a intenção de gerar um novo ponto de equilíbrio, singular universal. Num primeiro instante, essa relação de poder pode promover o equilíbrio, o que seria um fator positivo; porém, a longo prazo, poderia representar um sufocamento dos valores organizacionais, impedindo o rico processo de construção/reconstrução. O ponto de equilíbrio não significa valores permanentes, e sim que os processos de construção/reconstrução sempre agregam novos valores, permitindo nova singularidade mais adequada à realidade da ambiência organizacional, porém dentro do novo ponto de equilíbrio.

$\mathrm{Na}$ realidade, trabalhar com valores é uma questão por demais complexa, tendo em vista as múltiplas percepções que os indivíduos têm a respeito. Por exemplo, é comum confundir valor com habilidade técnica e conhecimento. Também é comum entender valores individuais como algo transmitido pelos pais, como uma questão imposta durante a educação escolar, como algo que é "depositado" no indivíduo sem que haja um processo de escolha/reflexão do que será absorvido. Observa-se também a ligação entre valores e desejos individuais. É igualmente comum o entendimento de valores individuais como dicotomia entre certo e errado.

Na realidade, mais uma vez queremos chamar a atenção de como os indivíduos percebem a questão dos valores, para que dirigentes se preocupem em buscar o valor singular da organização.

As percepções individuais acabam, como não podia deixar de ser, refletindo na forma como os valores organizacionais são conceituados pelo indivíduo. É comum perceber os valores organizacionais como "os valores da empresa", ou melhor, "dos donos da companhia"; "aqueles valores que a empresa preza", ou como "regras relativas ao relacionamento interpessoal na organização, como por exemplo seu código de ética e as normas ditadas por empresas". 


\section{Singularidade: caminho intrigante ou instigante}

Assim, fazemos um "convite à reflexão", propondo ao leitor efetuar rupturas no pensar, sentir e agir, a fim de substituir o que tradicionalmente se tem denominado "objetivos comuns por singularidade organizacional", somente alcançável através da construção, desconstrução e reconstrução de seus sistemas de valores.

Esse caminho não se constitui pela justaposição de valores individuais, mas em sua reconstrução permanente, a despeito das turbulências do percurso.

A singularidade organizacional não se atinge por meio do ensino e de práticas de planejamento estratégico, modelagem organizacional, logística, marketing e outros conteúdos, sem que se dê conta de que é necessário se tentar conviver - ensinando, se possível - com a turbulência, na construção da singularidade organizacional.

\section{Valores e mudança}

“...é preciso que saibamos que, sem certas dualidades ou virtudes como amorosidade, respeito aos outros, tolerância, humildade, gosto pela alegria, gosto pela vida, abertura do novo, disponibilidade à mudança, persistência na luta, recusa aos fatalismos, identificação com a esperança, abertura à justiça, não é possível a prática pedagógica-progressista, que não se faz apenas com ciência e técnica" (FREIRE, 1998).

Está cada vez mais desgastado o conceito de mudança desvinculado de valores. Fora de contexto pode apenas significar o deslocamento de qualquer objeto de um lugar para o outro. Quando percebido pelo olhar do administrador preocupado com os resultados de seu negócio, assume, preponderantemente, o significado de práticas instrumentais conducentes a um melhor desempenho da empresa, substitutas de outras consideradas ultrapassadas por não maximizarem lucros e vantagens. A própria modelagem organizacional, se entendida de forma fragmentada ou reducionista, pode nada significar como foco e instrumento desencadeador de mudança organizacional. Se despojada de valores (ocultos ou explícitos) sinalizadores de onde se desejaria chegar através do processo de mudança, na realidade, o que se altera? Já está instalada, portanto, a complexidade do tema. Assim, é urgente esclarecer o que é a mudança e, principalmente, como esta é desencadeada, o que pode garantir algum grau de perenidade e de real transformação.

O ponto de partida é a idéia de que mudar significa transformar; e que transformar não significa reformar, mudar ou inovar. Reforma, mudança, inovação apresentam-se para nós - a despeito da variedade de significados que possam ter - como visões reducionistas de um processo mais amplo, abrangente e revolucionário, que é o processo transformador

Dessa forma, o processo de transformação implica rupturas nos modos de pensar, sentir e agir e, assim, diz respeito a:

- reforma - em que alterações nas regras estabelecidas pela organização para comandar comportamentos constituem o foco central da mudança;

- mudança - em que a ênfase é dada nas modificações da estrutura formal da empresa, objetivando-se estabelecer novos padrões hierárquicos e, consequentemente, um poder formal;

- inovação - em que se busca a modernização da empresa, visando a adoção de novas tecnologias e procedimentos gerenciais considerados modernos e atuais.

Informar/romper é a ação pela qual algo se rompe. De saída, incorpora a idéia de interrupção ou cessação contratual em termos essencialmente psicológicos, sempre significando o rompimento de relações sociais no interior da organização e na sociedade.

Nesse sentido, surge uma pergunta inquietante e perturbadora: de onde nasce a ruptura e, consequentemente a transformação? Qualquer que seja o ponto de referência, independentemente do olhar, desassociado do campo 
de estudo/especialização do observador, percebe-se que a ruptura emerge de dentro para fora, a despeito de abordagens teóricas no campo da gestão que negam a importância do indivíduo no processo decisório organizacional, capaz de transformar o destino das pessoas e da sociedade. Desse modo, a transformação/ruptura procede da essência da condição humana; portanto, vem de valores que - ainda que construídos e transmitidos pelo aprendizado ao longo da vida - os indivíduos desconstroem e reconstroem incessante e permanentemente.

No sistema individual de valores - neste incluídas as crenças, ideologias e visão de mundo -, reside a semente capaz de transformar a organização em suas práticas cotidianas, permitindo alcançar estados de realização e satisfação, para não se falar em felicidade. E por que não? Sem aprofundamentos psicológicos ou filosóficos, verifica-se como o desejo de indivíduos na organização conduz à busca da felicidade pessoal, qualquer que seja a concepção individual dela.

Apesar de diagnósticos em sentido oposto que caracterizam essa visão como sonhadora, utópica, ou quimérica, completamente afastada da realidade do mundo e da vida organizacional, não há como negar a força que vem de dentro de cada indivíduo na organização. Não como simples adição ou justaposição, as forças de um, de outros e de todos - desde os que ostentam maiores parcelas de poder até os vistos como pobres de espírito e incompetentes - se mesclam num conjunto cuja tecitura se apresenta em contínuo como cores em dégradé, desde tons sombrios de hostilidade, exploração e exclusão até tonalidades leves e repousantes de amor, inclusão e doação.

Assim, a premissa dessa reflexão consiste na crença de que a mudança, entendida como transformação, advém dos valores dos indivíduos na organização e, portanto, íntimos e mais ou menos expressos em ações diuturnas. Por conseguinte, há de se falar em processo de construção, desconstrução e reconstrução de valores. Muitas vezes, esse processo poderá sofrer profunda reviravolta ou se estagnará na mesmice ou, ainda, se movimentará em direção ao retrocesso.

A arquitetura organizacional poderá servir de âncora ou impulso à transformação organizacional, na dependência dos valores individuais dos que integram a empresa. Como já se pretendeu esclarecer, esses valores não se apresentam estanques e imóveis. Não há imobilismo, nem isolamento de valores. No processo de reconstrução, aprende-se a reaprender. A interferência de valores que possam ser considerados organizacionais ou ambientais - conforme se queira enfatizar a endogenia organizacional em contraponto à exogenia ambiental - se torna flagrante e irrefutável, em função do referencial preferido pelo analista. Porém, tudo se atrela ao indivíduo, independentemente do repúdio de alguns a essa conclusão. Aliás, basta viver para obter evidências empíricas conducentes à veracidade da idéia central de nossa reflexão.

Não cremos na linearidade do pensamento, nem do processo de comunicação. Didaticamente, porém, a de começar a desenvolver e concluir. $\mathrm{O}$ fim representa novo começo, e assim por diante.

Repare-se como este texto revela os próprios valores de seus autores. Não pode ser de outro jeito. Em todas as situações existenciais, fora ou dentro da empresa, em atividades predominantemente de gestão ou em espaços formalmente construídos para instalação e ocorrência de processos ensino/aprendizagem, os valores individuais interagem e condicionam resultados e efeitos do empreendimento. Há valores comuns entre profissionais, capazes de configurar a arquitetura organizacional como elemento de convivência com a transformação. Alguns autores ressaltam, dentre outros, a humildade, a justiça, o amor ao próximo, demonstrando inequivocamente que a fonte da transformação brota do indivíduo e de seus valores. Por que, então, não nos inspirarmos na idéia de que o ponto de partida está em nós mesmos, para contribuirmos no processo de reconstrução do cotidiano organizacional? 


\section{Conclusão}

O conceito de singularidade organizacional nada tem de simples, como possa parecer à primeira vista. Em abordagens organizacionais tradicionais, cada organização tem sido vista como singular e única. Assim, a singularidade organizacional parece nada representar de novo. No entanto, a configuração da singularidade das organizações é um processo complexo, múltiplo e de visibilidade nada fácil. Isso ocorre porque só se cria essa singularidade através de um processo contínuo de construção, desconstrução e reconstrução de valores. Logo, delimitar a área de construção em que os valores individuais constroem os coletivos e interagem com os valores dos gestores em busca de um ponto de equilíbrio desejável constitui a essência da gestão contemporânea. Assim é que as organizações são vistas interna e externamente (figura 2).

Ademais, este estudo do processo de construção, desconstrução e reconstrução de valores se torna importante ferramenta de gestão, indispensável à sobrevivência das complexas organizações de hoje, já que a percepção externa é um imperativo que se manifesta através do cliente.

Finalmente, há de se perceber que o sistema de valores organizacionais sempre provém do humano, do ser em sua plenitude. Galeano (2001) já questionava: "o que são as pessoas de carne e osso? Para os economistas mais notórios, números. Para os banqueiros mais poderosos, devedores. Para os tecnocratas mais eficientes, incômodos. E para os políticos mais bem-sucedidos, votos".

E para os administradores quem são as pessoas de carne e osso? Este trabalho convida cada leitor a responder a pergunta. Estamos convictos de que a(s) resposta(s) só será(ão) encontrada(s) com base no entendimento dos valores individuais, do mesmo modo que na citação anterior o autor se referiu a economistas, banqueiros e políticos. 


\section{Referências bibliográficas}

CAPONIGRO, Jeffey. À beira de um ataque de nervos? Revista HSM Management, n.24, jan./fev. 2001.

CHANDRON, Shari. O que motiva os empregados. Revista HS Management, n.1, mar.- abr. 1997.

CHANLAT, Jean- François. 0 indivíduo na organização : dimensões esquecidas. São Paulo: Atlas, 1993, v.1, 2 e 3.

CLEGG, Stewart R.; HARDY, Cynthia; NORD, Walter R. (Orgs.). Handbook de estudos organizacionais. São Paulo: Atlas, 1998.

FORTUNA, Maria Lúcia Abranches. Gestão escolar e subjetividade. Niterói: Intertexto, 2000.

FREIRE, Paulo. Pedagogia da autonomia. Saberes necessários à prática administrativa. 7.ed. Rio de Janeiro: Paz e Terra, 1998.

GALBRAITH, Jay, et al. Organizando para competir no futuro. São Paulo: Makron Books, 1995.

GALEANO, Eduardo. Entrevista concedida à Globo News, nov. 2001.

KIDDER, Rushworth M. Shared values for a troubled word: conversation with men and women of conscience. San Francisco: Jossey Bass Publishers, 1994.

KOSLOWSKY, M eni; STASHEVSKY, Shmuel. (Ed.). Work values and organizational behavior toward the new milenium Jesuralém. ISAS International Seminars, 2000.

KOTTER, J. P. Leading change: why transformation efforts fail. Harvard Business Review, p.59-67, Mar./Apr. 2000.

LAWLER III, Eduard. Estratégias versus funcionários. Revista HSM Management, n.10, set./out. 1998.

LEONE, Nilda Guerra. O comportamento empresarial influenciado pelo jogo permanente do sistema de valores e atitudes do dirigente. Revista de Administração Publica, Rio de Janeiro, v.25, n.2, p.103-113, abr./jun. 1991.

RESCHER, Nicholas. Introduction to value theory. New Jersey: Prentice- Hall, 1969.

SCHELER, Max. Da reviravolta dos valores. Petrópolis: Vozes, 1994.

TOMEl, Patrícia Amelia. Inveja nas organizações. São Paulo: Makron Books, 1994. 